\title{
Total and partial laparoscopic adrenalectomy
}

Contact:wmbernardo@usp.br

1. Sociedade Brasileira de Urologia, Rio de Janeiro, RJ, Brasil 2. Associação Médica Brasileira, São Paulo, SP, Brasil

Question: Adrenalectomy (laparoscopic) for patients with subclinical Cushing's syndrome?

(Page 582)

Answer: There are benefits in the surgical treatment (laparoscopic) for reducing the risk of metabolic syndrome (glucose intolerance), hypertension, and dys- lipidemia in patients with subclinical Cushing's syndrome (Page 584).

\section{REFERENCE}

Silvinato A, Bernardo WM, Branco AW. Total and partial laparoscopic adrenalectomy. Rev Assoc Med Bras 2019; 65(5):579-586. 